\title{
Highly transparent and conductive annealed ZnO nanoparticles thin film prepared by pulsed laser deposition
}

\author{
M. Ali, M. Salah ", M. M. El-Desoky \\ Physics Department, Faculty of Science, Suez University, Suez, 43518, Egypt
}

\section{ARTICLE INFO}

Article history:

Received 28 January 2022

Received in revised form 30 January 2022

Accepted 31 January 2022

Available online 2 February 2022

\section{Keywords}

Thin film,

Microwave,

GIXRD

electrical properties. \begin{abstract}
A thin film can be applied to a wide variety of microelectronic devices, sensors, antireflective and protective coatings, transparent electrodes, etc. It increases the efficiency and versatility of the equipment. The nanostructured particles of zinc oxide $(\mathrm{ZnO})$ were synthesized using a microwave method with an average grain size of $25.7 \mathrm{~nm}$. Highquality $\mathrm{ZnO}$ thin films are being deposited using the Pulsed Laser Deposition (PLD) technique at room temperature, one of the most advanced Physical Vapor Deposition techniques. After one hour of air annealing at $400{ }^{\circ} \mathrm{C}$, grazing incident X-ray diffractometer (GIXRD) confirms polycrystalline hexagonal wurtzite formation with an average grain size of $7.7 \mathrm{~nm}$. The transmission spectrum indicates high transparency in the visible region, with an average value of $95 \%$. The calculated activation energy and dc conductivity were $32 \mathrm{meV}$ and $950 \Omega^{-1} \cdot \mathrm{m}^{-1}$, respectively. The highly transparentconductive $\mathrm{ZnO}$ thin film may present a new avenue for electrodes with transparent conductivity.
\end{abstract}

\section{Introduction}

Zinc oxide is a technologically significant material that displays multifunctional properties [1 - 4]. This material is effective in a wide variety of optoelectronic device applications, such as transparent electrodes, solar cells, gas sensors, flat panel displays, smart windows, and thinfilm resistors [1, $4-6]$. Recently, several studies have been conducted on transparent conducting electrodes [1 12]. According to B. Benhaoua et al. [7], Al-doped $\mathrm{ZnO}$ thin films were prepared using the ultrasonic spray technique. The influences of Al-doping on structural, optical, and electrical properties of the annealed $\mathrm{ZnO}$ thin films were measured. The average transmittance and electrical conductivity of the films were found to be $80 \%$ and $19 \Omega$ ${ }^{1} \cdot \mathrm{m}^{-1}$, respectively. A. Gahtar et al. [8] deposited $\mathrm{ZnO}$ and Al-doped $\mathrm{ZnO}$ films on substrates of glass using the ultrasonic spray technique. The effects of ethyl alcohol and methanol solutions on the structural, optical, and electrical properties of the thin films before and after doping were examined. All films show average optical transparency of about $90 \%$ in the visible spectrum. Using a sol-gel method, $\mathrm{X}$. Liu et al. [9] have prepared transparent conducting Aldoped $\mathrm{ZnO}$ thin films on quartz substrates. The conductivity of the films increases from $31 \Omega^{-1} \cdot \mathrm{m}^{-1}$ to 70.4 $\Omega^{-1} \cdot \mathrm{m}^{-1}$, while the average transmission in the visible region increases from $82.9 \%$ to $86.7 \%$.

* Corresponding authors at Suez University

E-mail addresses: mohamed.ayoub@suezuniv.edu.eg (M. Salah)
A. Al-Ghamdi et al. [10] have deposited thin films of Aldoped $\mathrm{ZnO}$ using spin coating technique onto glass substrates. The electrical conductivity was increased to $100 \Omega^{-1} \cdot \mathrm{m}^{-1}$ by increasing the Al-doping concentration to 4 wt \%. As a result, Al-doped $\mathrm{ZnO}$ thin films reveal high transparency in the visible region with an average value of $86 \%$.

In our study, the annealed $\mathrm{ZnO}$ thin film fabricated by the PLD technique was characterized for its structural, optical, and electrical properties. The results showed that the annealed film at $400{ }^{\circ} \mathrm{C}$ for 1 hour exhibits a transparent-conductive behavior.

\section{Experimental procedures}

The thin films of $\mathrm{ZnO}$ were deposited using a PLD system on glass substrates. By using a microwave method [11], the nanoscale particles of $\mathrm{ZnO}$ with an ultra-high purity were produced. Nanoparticles of $\mathrm{ZnO}$ have an average grain size of $25.7 \mathrm{~nm}$. The glass sheets used as substrates for thin films formation of $\mathrm{ZnO}$ were pre-cleaned in an ultrasonic bath for 5 minutes with ethyl alcohol before inserting them into the apparatus. Then, using a $3 \mathrm{~cm}$ distance between each substrate and the target surface, they were placed parallel to each other. In this experiment, a Q-switched Nd:YAG laser ( $=532 \mathrm{~nm}$, pulse width $6 \mathrm{~ns})$ was used at a repetition rate of $10 \mathrm{~Hz}$. At a $45^{\circ}$ angle of incidence, the laser beam was focused onto the $\mathrm{ZnO}$ nanoparticles by a $20 \mathrm{~cm}$ focal lens. The powder nanoparticles are rotated at a constant speed during deposition to prevent drilling and ensure a smooth film deposition. The laser beam energy was set around 18.2 
mJoules per pulse during the experiment, which produced nearly $137.6 \mathrm{~J} / \mathrm{cm}^{2}$ of energy density at the target surface. Turbo-molecular and rotary pumps evacuate the thin-film production chamber to $8 \times 10^{-4} \mathrm{~Pa}$. In the evacuation chamber, $\mathrm{ZnO}$ thin films were deposited for 5 minutes at room temperature. Based on absorption measurements, the film layer depth was about $105 \mathrm{~nm}$. Thin films of $\mathrm{ZnO}$ were fabricated at room temperature; annealed in an open atmosphere for one hour at $400^{\circ} \mathrm{C}$.

The crystal structure and particle dimensions of the thin films were characterized by grazing incident X-ray diffractometer (GIXRD) pattern using $\mathrm{Cu} \mathrm{K}_{\alpha}$ radiation (Panalytical, X'Pert Pro, Netherlands). The GIXRD data were collected for $2 \theta$ at $20^{\circ}$ to $80^{\circ}$ with a resolution of $0.02^{\circ}$. The morphology of the annealed film was investigated by scanning electron microscope (SEM), Model Quanta 250 Field Emission Gun, Netherlands. An optical transmittance measurement was performed on $\mathrm{ZnO}$ film by UV/Visible spectrometer (Model T80+, PG Instruments Limited) in the wavelength range of $0.200-$ $0.800 \mathrm{~mm}$. A multimeter (ISO-TECHIDM 303) was used to collect the dc conductivity data, measured by the two-probe method with silver paste electrodes. The dc conductivity measurements were conducted over a temperature range of 300 to $450 \mathrm{~K}$.

\section{Results and discussion}

Figure 1 reveals a GIXRD pattern of the prepared thin film of $\mathrm{ZnO}$ on the glass substrate annealed at $400{ }^{\circ} \mathrm{C}$ for 1 h. The diffraction peaks indicate a nanocrystalline structure. In the GIXRD pattern, the annealed film shows (002) as its preferred orientation peak. Furthermore, more peaks are observed at (100), (101), (102), (110), (103), and (112). JCPDS card no. 04-015-0825, which is used to evaluate these results, agrees well. As a result, the annealed thin films of $\mathrm{ZnO}$ exhibited hexagonal crystallization in the preferred $c$-axis direction perpendicular to the surface of the substrate [11].

According to Debye-Sherrer's formula [12, 13], the average crystallite size of the $\mathrm{ZnO}$ annealed thin film was $7.7 \mathrm{~nm}$ :

$$
D=k \lambda /(\beta \cos \Theta)
$$

where $(D)$ is the crystallite size, $(\mathrm{k} \sim 1)$ is the correction factor, $(\lambda=0.15406 \mathrm{~nm})$ is the wavelength of $\mathrm{Cu}-\mathrm{K}_{\alpha}$ radiation, $(\Theta)$ is the angle of diffraction, and $(\beta)$ is the full width half maximum (FWHM) of the most intense peak in units of radians.

Microscopy of thin films using SEM is a convenient way of studying their microstructure. The $\mathrm{ZnO}$ thin film annealed on a glass substrate is depicted in fig. 2, which shows an SEM surface micrograph. The annealed thin film fabricated using $\mathrm{ZnO}$ nanoparticle targets exhibits rough surface properties and compact crystalline grains of different sizes can be observed in a spherical shape.

Figure 3 shows the spectra of optical transmission of $\mathrm{ZnO}$ thin film annealed at $400{ }^{\circ} \mathrm{C}$ for an hour. In the spectral range $0.400-0.800 \mathrm{~mm}$, the average transmittance of the films is about $95 \%$. In the annealed film, the sharp fall in transmittance at the absorbance edge illustrates the direct bandgap and crystalline characteristics of the annealed film.

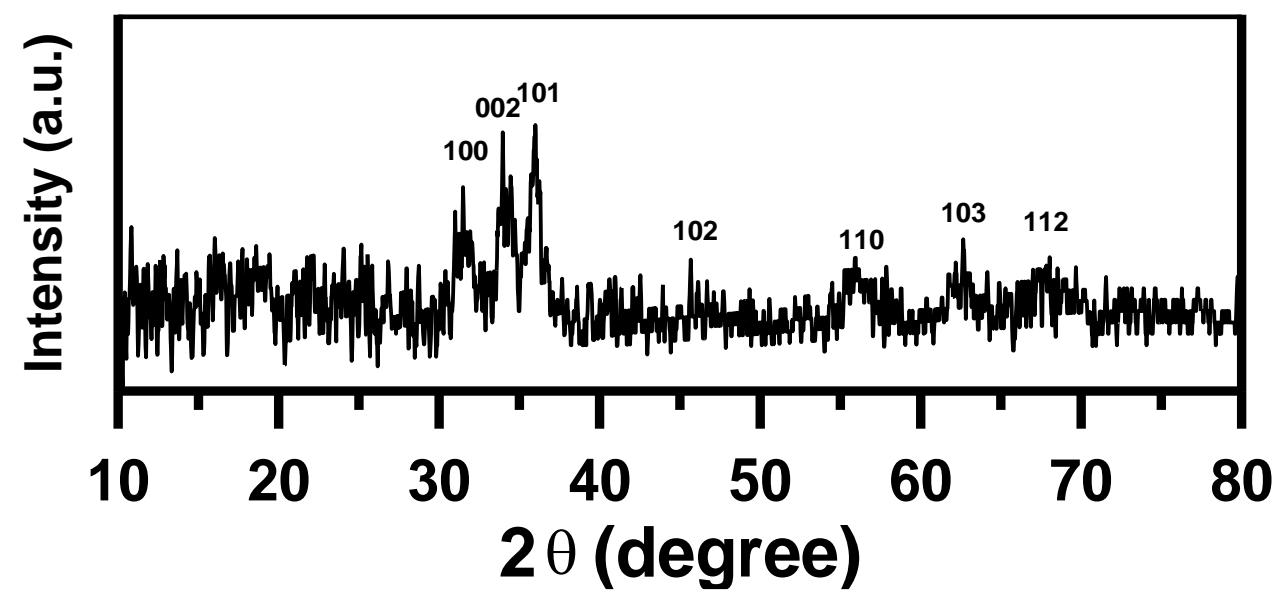

Fig. (1): GIXRD pattern of $\mathrm{ZnO}$ thin films annealed at $400^{\circ} \mathrm{C}$ for $1 \mathrm{~h}$. 


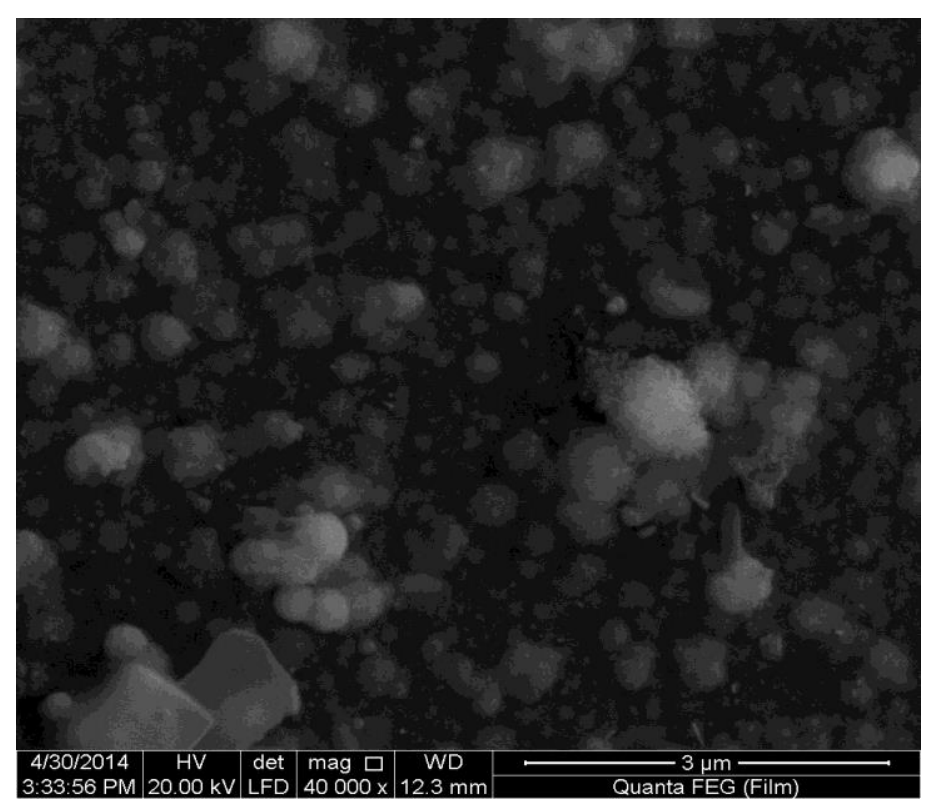

Fig. (2): SEM image of the annealed $\mathrm{ZnO}$ thin film.

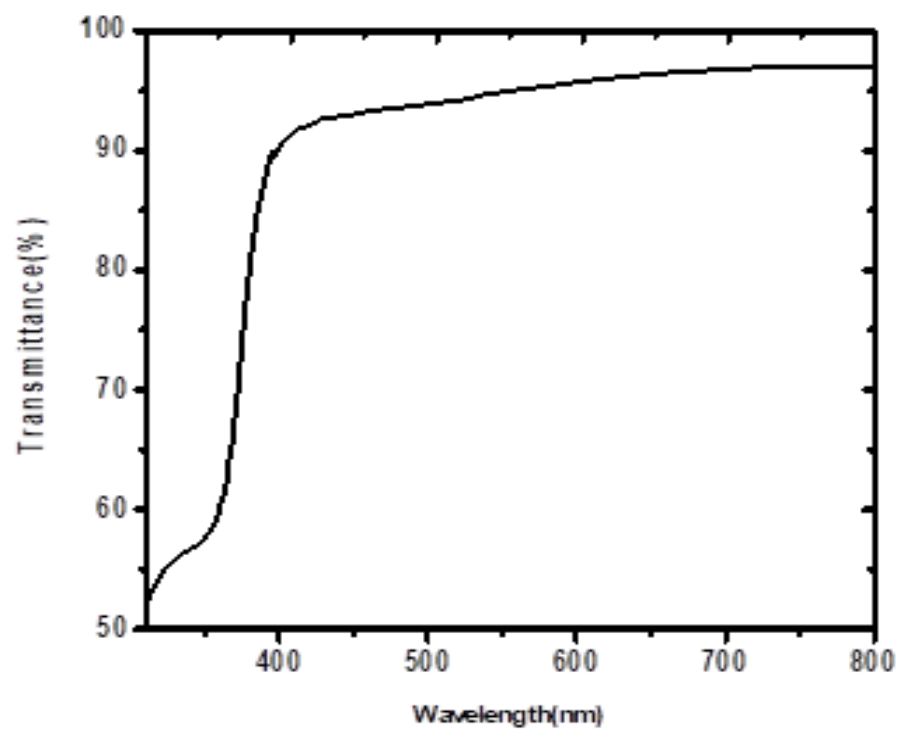

Fig. (3): The transmission spectra of the annealed $\mathrm{ZnO}$ thin film.

Figure 4 shows an Arrhenius relation [11] accordance with a semiconducting temperature variation of the $\mathrm{dc}$ conductivity $(\sigma)$ of $\mathrm{ZnO}$ thin film annealed at $400{ }^{\circ} \mathrm{C}$ for 1 hour:

$$
\sigma=\sigma_{0} e^{-E_{a} / k_{B} T}
$$

Where $\sigma_{0}, E_{\mathrm{a}}, K_{\mathrm{B}}$ and $T$ are the pre-exponential factor, activation energy, Boltzmann's constant, and absolute temperature, respectively. The activation energy was calculated from the slope of the curve for the film and the pre-exponential factor was obtained from the interception of the least square straight-line fits of the data.

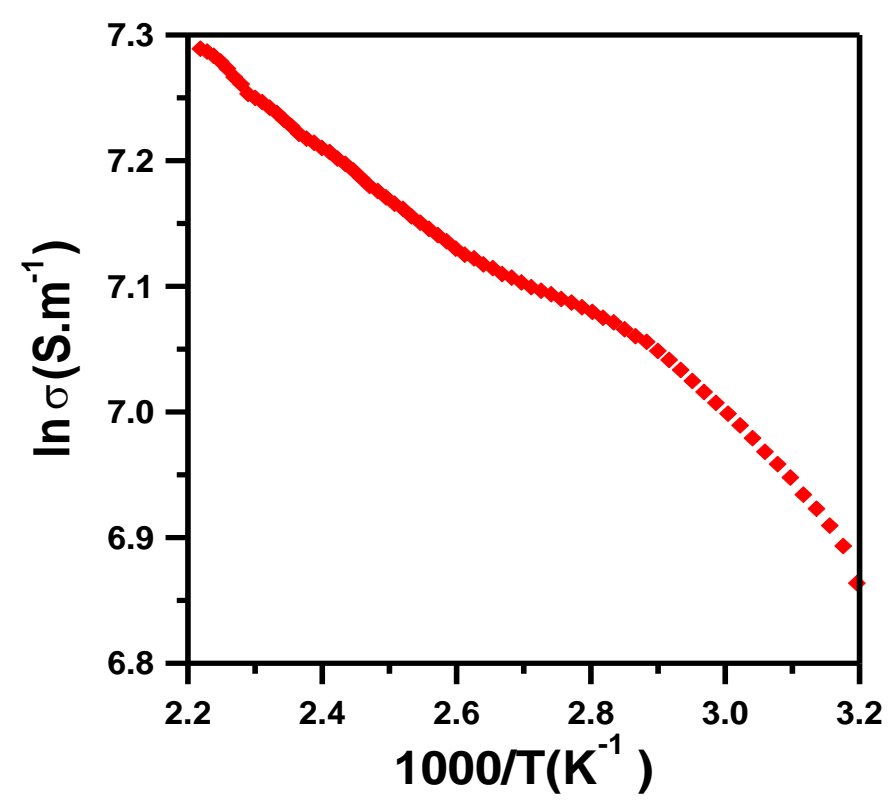

Fig (4): Variation of dc conductivity ( $\ln \sigma$ ) as a function of the inverse of temperature $\left(\mathrm{T}^{-1}\right)$ for $\mathrm{ZnO}$ thin films annealed at $400^{\circ} \mathrm{C}$ for $1 \mathrm{~h}$.

As in semiconductors, the straight line form of the Arrhenius relation indicates that conduction is thermally activated.

The calculated $\sigma_{0}$ and $E_{\mathrm{a}}$ for the annealed thin film were $8.109 \Omega^{-1} \cdot \mathrm{m}^{-1}$ and $0.032 \mathrm{eV}$, respectively [11]. Furthermore, $\sigma$ was found to be $950 \Omega^{-1} \cdot \mathrm{m}^{-1}$ at room temperature. According to Arrhenius equation (2), the large difference between the two conductivities arises from the dc conductivity at $300 \mathrm{~K}$, which is exponentially related to the pre-exponential factor that is the theoretical $\mathrm{dc}$ conductivity at $0 \mathrm{~K}$. Finally, the high transmittance and high conductivity of annealed $\mathrm{ZnO}$ thin films annealed for 1 hour at $400{ }^{\circ} \mathrm{C}$ may open a new avenue for transparentconductive electrode application in the near future.

\section{Conclusion}

A thin $\mathrm{ZnO}$ film is deposited on a glass substrate at $300 \mathrm{~K}$ using the PLD technique. The fabricated film is then annealed for 1 hour at $400{ }^{\circ} \mathrm{C}$ in the air. We investigated the effects of annealing temperature on the structure, surface morphology, optical, and electrical properties of annealed $\mathrm{ZnO}$ thin films with GIXRD, SEM, UV/Vis spectrophotometer, and dc conductivity. GIXRD revealed that the nanocrystals had a size of $7.7 \mathrm{~nm}$. The SEM image shows rough surface and crystalline grains in spherical shapes. There is a high level of transparency in the visible region, with an average value of $95 \%$. The dc conductivity and the activation energy at room temperature are $950 \Omega$ ${ }^{1} \mathrm{~m}^{-1}$ and $0.032 \mathrm{eV}$, respectively. Thin films of annealed $\mathrm{ZnO}$, which are highly transparent and conductive, can be used as transparent conductive electrodes in solar cells. 


\section{Acknowledgments}

M. Salah was funded by a scholarship (JS3809) from the Ministry of Higher Education of Egypt.

\section{Reference}

1. Ciolan MA, Motrescu I. Pulsed Laser Ablation: A Facile and Low-Temperature Fabrication of Highly Oriented n-Type Zinc Oxide Thin Films. Applied Sciences. 2022; 12: 917.

2. Kim YS, Ha S-C, Kim K, Yang H, Choi S-Y, Kim YT, et al. Room-temperature semiconductor gas sensor based on nonstoichiometric tungsten oxide nanorod film. Applied Physics Letters. 2005; 86: 213105

3. Huang $\mathrm{H}$, Tan OK, Lee YC, Tran TD, Tse MS, Yao X. Semiconductor gas sensor based on tin oxide nanorods prepared by plasma-enhanced chemical vapor deposition with postplasma treatment. Applied Physics Letters. 2005; 87: 163123.

4. Zuruzi AS, Kolmakov A, MacDonald NC, Moskovits M. Highly sensitive gas sensor based on integrated titania nanosponge arrays. Applied Physics Letters. 2006; 88: 102904.

5. Laurenti M, Cauda V. Porous Zinc Oxide Thin Films: Synthesis Approaches and Applications. Coatings. 2018; 8: 67.

6. Hara K, Horiguchi T, Kinoshita T, Sayama K, Sugihara H, Arakawa $\mathrm{H}$. Highly efficient photon-to-electron conversion with mercurochrome-sensitized nanoporous oxide semiconductor solar cells. Solar Energy Materials and Solar Cells. 2000; 64: 115.

7. Benhaoua B, Rahal A, Benramache S. The Structural, optical and electrical properties of nanocrystalline $\mathrm{ZnO}: \mathrm{Al}$ thin films. Superlattices and Microstructures. 2014; 68: 38.

8. Gahtar A, Rahal A, Benhaoua B, Benramache S. A comparative study on structural and optical properties of $\mathrm{ZnO}$ and Al-doped $\mathrm{ZnO}$ thin films obtained by ultrasonic spray method using different solvents. Optik. 2014; 125: 3674.

9. Al-Ghamdi AA, Al-Hartomy OA, El Okr M, Nawar AM, ElGazzar S, El-Tantawy F, et al. Semiconducting properties of Al doped $\mathrm{ZnO}$ thin films. Spectrochimica Acta Part A: Molecular and Biomolecular Spectroscopy. 2014; 131: 512.

10. Liu X, Pan K, Li W, Hu D, Liu S, Wang Y. Optical and gas sensing properties of $\mathrm{Al}$-doped $\mathrm{ZnO}$ transparent conducting films prepared by sol-gel method under different heat treatments. Ceramics International. 2014; 40: 9931.

11. Goyal DJ, Agashe C, Takwale MG, Bhide VG, Mahamuni S, Kulkarni SK. Dopant induced modifications in the physical properties of sprayed ZnO:In films. Journal of Materials Research. 1993; 8: 1052.

12. Hsu C-C, Wu NL. Synthesis and photocatalytic activity of $\mathrm{ZnO} / \mathrm{ZnO} 2$ composite. Journal of Photochemistry and Photobiology A: Chemistry. 2005; 172: 269.

13. Salah M, Morad I, Ali HE, Mostafa MM, El-Desoky MM. Influence of $\mathrm{BaO}$ Doping on the Structural, Ac Conductivity, and Dielectric Properties of BiFeO3 Multiferroic Nanoparticles. Journal of Inorganic and Organometallic Polymers and Materials. 2021; 31: 3700.

14. Al-Assiri MS, Mostafa MM, Ali MA, El-Desoky MM. Synthesis, structural and electrical properties of annealed $\mathrm{ZnO}$ thin films deposited by pulsed laser deposition (PLD). Superlattices and Microstructures. 2014; 75: 127.

15. El-Desoky MM, Mostafa MM, Ayoub MS, Ahmed MA. Transport properties of $\mathrm{Ba}$-doped $\mathrm{BiFeO} 3$ multiferroic nanoparticles. Journal of Materials Science: Materials in Electronics. 2015; 26: 6793. 